\title{
P100 Polymyositis-scleroderma Autoantigen Antibody Measurement
}

National Cancer Institute

\section{Source}

National Cancer Institute. P100 Polymyositis-scleroderma Autoantigen Antibody

Measurement. NCI Thesaurus. Code C120651.

The determination of the P100 polymyositis-scleroderma autoantigen antibody present in a sample. 